\title{
Long-term follow-up, computed tomography, and computational fluid dynamics of the Cabrol procedure
}

\author{
Joseph Knight, MS, ${ }^{\text {a }}$ Stephan Baumüller, MD, ${ }^{\mathrm{b}}$ Vartan Kurtcuoglu, $\mathrm{PhD}, \mathrm{MD},{ }^{\mathrm{a}}$ Marko Turina, MD, ${ }^{\mathrm{c}}$ \\ Juraj Turina, MD, ${ }^{\mathrm{d}}$ Ulrich Schurr, MD,${ }^{\mathrm{c}}$ Dimos Poulikakos, PhD,${ }^{\mathrm{a}}$ William Marshall, Jr, MD, ${ }^{\mathrm{e}}$ and \\ Hatem Alkadhi, MD ${ }^{\text {b,f }}$
}

\begin{abstract}
Objectives: The Cabrol procedure is characterized by insertion of an ascending aortic composite graft with reimplantation of the coronary arteries by the interposition of a graft tube. Our purpose is to report the clinical long-term follow-up and computed tomographic findings in patients having undergone the Cabrol procedure and to determine blood flow in the Cabrol graft using computational fluid dynamics.
\end{abstract}

\begin{abstract}
Methods: Clinical follow-up ( $76.6 \pm 16.6$ months) and dual-source computed tomographic angiography data of 7 patients (all men, mean age $54.9 \pm 9.6$ years) with 12 Cabrol grafts (left main coronary artery, $\mathrm{n}=7$; right coronary artery, $\mathrm{n}=5$ ) were reviewed. In 2 patients, the right coronary artery was directly reattached to the aortic graft. Computational fluid dynamics were calculated using computed tomographic data of a patient with the Cabrol procedure and compared with those in a Valsalva graft and a healthy aortic root.
\end{abstract}

Results: Computed tomography showed Cabrol graft occlusions to 1 of $7(14 \%)$ left main and of 2 of 5 (40\%) right coronary arteries. Six grafts to the left main and 3 to the right coronary artery were fully patent, similar to the 2 directly reattached right coronary arteries to the aortic graft. Computational fluid dynamics results show similar blood flow parameters into the coronaries for the healthy aortic root and Valsalva graft. In the Cabrol graft, a spiraling flow pattern with low flow into the right coronary artery was found (right coronary artery $=1 \mathrm{~mL} /$ min at both systole and diastole).

Conclusions: Our study indicates low flow rates particularly in the right Cabrol graft correlating with a higher incidence of occlusions of the right as compared with the left Cabrol graft at long-term follow-up. (J Thorac Cardiovasc Surg 2010;139:1602-8)

Several techniques are currently available for the surgical replacement of the aortic root. These procedures include a replacement graft for the ascending aorta and can be associated with or without concomitant aortic valve replacement. The replacement graft can be a straight cylindrical type or one with Valsalva shape that more accurately mimics normal aortic root flow for the valve and into the coronary ostium. ${ }^{1,2}$

The button technique has become the standard method of reattachment of the coronary arteries. ${ }^{3}$ For instances in which the button technique is not applicable, ${ }^{4,5}$ for example,

From the Laboratory of Thermodynamics in Emerging Technologies, ${ }^{\mathrm{a}}$ Department of Mechanical and Process Engineering, ETH Zurich, Switzerland; the Institute of Diagnostic Radiology, ${ }^{\mathrm{b}}$ Clinic for Cardiovascular Surgery, ${ }^{\mathrm{c}}$ and Cardiovascular Center, ${ }^{\mathrm{d}}$ University Hospital Zurich, Zurich, Switzerland; the College of Medicine, ${ }^{\mathrm{e}}$ University of South Florida, Tampa, Fla; and the Cardiac MR PET CT Program, ${ }^{\mathrm{f}}$ Massachusetts General Hospital and Harvard Medical School, Boston, Mass.

Supported by the National Center of Competence in Research, Computer Aided and Image Guided Medical Interventions of the Swiss National Science Foundation.

Disclosures: None.

Received for publication July 23, 2009; revisions received Sept 4, 2009; accepted for publication Sept 17, 2009; available ahead of print Nov 13, 2009.

Address for reprints: Hatem Alkadhi, MD, Cardiac MR PET CT Program, Massachusetts General Hospital and Harvard Medical School, Boston, MA 02114 (E-mail: halkadhi@partners.org).

0022-5223/\$36.00

Copyright (c) 2010 by The American Association for Thoracic Surgery doi:10.1016/j.jtcvs.2009.09.023 during reoperative procedures or in cases in which the coronary arteries are challenging to mobilize, the Cabrol procedure can be used. ${ }^{6}$ In this now rarely applied procedure, an additional smaller diameter graft (Dacron or polytetrafluoroethylene) is anastomosed side to side with the ascending aortic graft and end to end to the coronary attachments.

It has previously been shown that the specific technique of coronary reimplantation (Bentall, "button," or Cabrol procedure) is significantly associated with the outcomes of aortic root replacement. ${ }^{5}$ However, while Cabrol and associ$\operatorname{ates}^{7}$ reported a very positive 5 -year outcome in 30 patients (20 aneurysm, 10 dissection), Gelsomino and colleagues ${ }^{3}$ advise against the use of the Cabrol procedure on the basis of their 16-year follow-up in 45 patients (17 dissection, 10 annuloaortic ectasia, 5 atherosclerotic aneurysm, 7 bicuspid aortic valve, and 6 previous aortic surgery). It is not known which factors led to this disparity between the studies. Nevertheless, the consensus today is that the button technique should be used in general, whereas the Cabrol procedure should be performed only when the former is not possible. ${ }^{3,8-10}$

In this study, we report clinical long-term follow-up data and dual-source computed tomography (CT) imaging findings in 7 patients having undergone the Cabrol procedure. In addition, we describe blood flow patterns based on 


\section{Abbreviations and Acronyms \\ $\mathrm{CFD}=$ computational fluid dynamics \\ $\mathrm{CT}=$ computed tomography \\ $\mathrm{LAD}=$ left anterior descending coronary artery \\ LCX $=$ left circumflex coronary artery \\ $\mathrm{RCA}=$ right coronary artery}

calculations of computational fluid dynamics (CFD) using CT data sets of a patient treated with the Cabrol procedure; we compare them with those in a Valsalva graft and a normal healthy aortic root. Finally, on the basis of these calculations, we provide potential factors to better understand the reported negative outcomes of the Cabrol procedure.

\section{METHODS}

\section{Patient Population}

Between November 1980 and December 2004, 405 consecutive patients underwent a redo procedure of replacement of the aortic valve or root and/or composite replacement valve in our hospital. The Cabrol procedure was used in $6.2 \%$ (25) of patients undergoing a composite ascending aorta and aortic valve replacement. The indications for using the Cabrol procedure were generally redo procedures, extensive calcification of the aneurysmal aorta, and low coronary ostia. From these 25 patients, 6 were lost to follow-up and 12 died. Death was unrelated to the Cabrol procedure but rather caused by the severe general cardiovascular morbidity of the patients. Thus, we included 7 patients (all men, mean age $54.9 \pm 9.6$ years, range 40-72 years) in our study. The study had local ethics committee approval; written informed consent was obtained from all patients.

\section{Cabrol Procedure}

The Cabrol procedure represents a coronary connection to the aortic root conduit that consists of inserting an 8- or 10-mm Dacron tube in an end-toend fashion between the 2 coronary ostia and anastomosing this tube in a side-to-side manner on the right side of the aortic tube. ${ }^{6,7}$ This was called by Cabrol himself a "moustache." When only one coronary artery was grafted, the procedure is called a "hemi-Cabrol."

\section{Clinical Follow-up}

All clinical data were obtained by retrospective review of medical records. Postoperative follow-up information was obtained by periodic cardiologic reports and questionnaires. Cumulative follow-up totaled 44.67 patient-years. Clinical follow-up extended to a maximum of 104 months and the mean follow-up interval was $76.6 \pm 16.6$ months (median 74 months)

\section{CT}

All patients underwent imaging with a dual-source CT scanner (Somatom Definition, Siemens Medical Solutions, Forchheim, Germany). Details of scan protocol and data acquisition parameters can be found in Alkadhi and associates. ${ }^{11}$ Electrocardiographic pulsing for radiation dose reduction was used in all patients, ${ }^{12}$ leading to an average effective radiation dose of 7 to $9 \mathrm{mSv}^{13}$

\section{CFD}

Geometries. Computer models of the geometries of interest were generated by image segmentation of dual-source CT data sets of a normal aortic root, a Valsalva graft, and of a patient having undergone the Cabrol proce- dure. Each model included the aortic root and proximal part of the ascending aorta, as well as proximal segments of the right (RCA), left anterior descending (LAD), and left circumflex (LCX) coronary arteries. Two variations of each model representing maximal flow during the systolic and diastolic phases of the cardiac cycle were used.

For the normal aortic root under diastolic conditions, the aortic valve was taken into account in the closed position. The valve was placed in an open position for the systolic phase, thus partially covering the sinus of Valsalva openings.

Models of the two anatomies altered by pseudosinus graft replacement and the Cabrol procedure were created in a similar fashion, again including the proximal portions of the right and left coronary arteries and also the additional graft for the Cabrol procedure.

Boundary conditions. For a CFD study to be performed, as previously shown, ${ }^{14}$ boundary conditions, for example, prescribed values of velocity or pressure at the inlets and outlets of the respective domain, have to be used. Inasmuch as we are specifically concerned with comparing the effect of changes in geometry of these procedures on the corresponding flow, we developed the strategy described herein to allow direct comparison of the models.

Steady boundary conditions were used at maximal flow rates of the systolic and diastolic phases of the cardiac cycle in the normal anatomy case. In diastole, an inlet pressure of $110 \mathrm{~mm} \mathrm{Hg}$ was set at the distal end of the ascending aortic geometry. Flow rates were specified at the 3 outlets $(\mathrm{LAD}=67 \mathrm{~mL} / \mathrm{min}, \mathrm{LCX}=33 \mathrm{~mL} / \mathrm{min}$, and RCA $=12 \mathrm{~mL} / \mathrm{min})$. The pressures at the outlets were then computed and considered to be the natural back pressure of the downstream sections of the coronary arteries and the capillary beds in diastole. These outlet pressures were subsequently used as the coronary artery boundary conditions for the 2 surgical models in diastole, while the same inlet pressure as in the normal anatomy $(110 \mathrm{~mm}$ $\mathrm{Hg}$ ) was applied at the distal end of the ascending aorta geometry.

An analogous procedure was used for the systolic boundary conditions. A steady solution at maximal systolic flow in the normal anatomy geometry was first obtained. A flow rate of $5 \mathrm{~L} / \mathrm{min}$ was set at the aortic annulus. An outlet pressure of $120 \mathrm{~mm} \mathrm{Hg}$ was set at the distal end of the ascending aortic geometry. Flow rates where then specified at the 3 outlets $(\mathrm{LAD}=33 \mathrm{~mL} /$ $\min , \mathrm{LCX}=17 \mathrm{~mL} / \mathrm{min}$, and $\mathrm{RCA}=15 \mathrm{~mL} / \mathrm{min}$ ). The herewith calculated outlet pressures were subsequently used as the coronary artery outlet conditions for the 2 surgical models.

CFD settings. Blood was modeled as an noncompressible Newtonian fluid $^{15}$ with a density of $1050 \mathrm{~kg} / \mathrm{m}^{3}$ and a viscosity of 0.003 Pascal seconds. An unstructured tetrahedral grid was generated for each model in ICEMCFD (ANSYS Inc, Pittsburgh, Pa). Simulations were performed in CFX 11.0 (ANSYS Inc).

\section{RESULTS}

\section{Clinical Follow-up}

The clinical conditions necessitating primary heart surgery as well as the diseases at the time of the reoperation using the Cabrol procedure are listed in Table 1.

The clinical follow-up at the time of CT showed good general conditions with no clinical or physical limitations (New York Heart Association class I) in 5 of 7 (71.4\%) patients. One patient (No. 2 in the table) had bradyarrhythmia, but no signs of heart failure were found. One patient (No. 4 in the table) had fatigue and a reduction of physical performance in everyday life (New York Heart Association class II). In addition, the patient reported palpitations at night and recurrent chest pain. No signs of heart failure were found in this patient. 
TABLE 1. Demographic data, underlying disease at the time of the Cabrol procedure, follow-up time interval, and CT findings in the 7 patients of this study

\begin{tabular}{|c|c|c|c|c|c|}
\hline No./age/gender & $\begin{array}{l}\text { Follow-up } \\
\text { interval }\end{array}$ & $\begin{array}{l}\text { Primary disease and } \\
\text { primary surgical } \\
\text { procedure }\end{array}$ & Underlying disease & Cabrol graft at CT & Additional CT findings \\
\hline $1 / 42 / \mathrm{M}$ & $7 \mathrm{y}, 1 \mathrm{mo}$ & $\begin{array}{l}\text { Annulo-aortic ectasia with } \\
\text { severe AR } \\
\text { AVR with homograft of the } \\
\text { aortic root }\end{array}$ & $\begin{array}{l}\text { Degenerated homograft with } \\
\text { severe AR and } \\
\text { periprosthetic aneurysm }\end{array}$ & $\begin{array}{l}\text { Left patent } \\
\text { Right occluded }\end{array}$ & - \\
\hline 2/63/M & $4 \mathrm{y}, 10 \mathrm{mo}$ & $\begin{array}{l}\text { Severe degenerative AS } \\
\text { Mechanical AVR }\end{array}$ & $\begin{array}{l}\text { Paravalvular regurgitation of } \\
\text { mechanical AV }\end{array}$ & $\begin{array}{l}\text { Left graft patent } \\
\text { Directly attached } \\
\text { RCA patent* }\end{array}$ & - \\
\hline 3/72/M & $5 \mathrm{y}, 4 \mathrm{mo}$ & $\begin{array}{l}\text { Infective endocarditis } \\
\text { Mechanical AVR }\end{array}$ & $\begin{array}{l}\text { Severe AR and ascending } \\
\text { aortic aneurysm }\end{array}$ & Both patent & $\begin{array}{l}\text { Subtotally thrombosed } \\
\text { periprosthetic aneurysm }\end{array}$ \\
\hline $4 / 62 / \mathrm{M}$ & $8 \mathrm{y}, 3 \mathrm{mo}$ & $\begin{array}{l}\text { Acute type A dissection } \\
\text { Mechanical AVR and } \\
\text { supracoronary aortic graft }\end{array}$ & $\begin{array}{l}\text { Aneurysm of the sinus of } \\
\text { Valsalva with rupture } \\
\text { into the left atrium }\end{array}$ & Both patent & $\begin{array}{l}\text { Fully patent periprosthetic } \\
\text { aneurysm }\end{array}$ \\
\hline $5 / 56 / \mathrm{M}$ & $8 \mathrm{y}, 8 \mathrm{mo}$ & $\begin{array}{l}\text { Acute type A dissection } \\
\text { Supracoronary aortic graft }\end{array}$ & $\begin{array}{l}\text { AR combined with } \\
\text { periprosthetic aneurysm }\end{array}$ & $\begin{array}{l}\text { Left patent Right } \\
\text { subtotally occluded }\end{array}$ & $\begin{array}{l}\text { Subtotally thrombosed } \\
\text { periprosthetic aneurysm }\end{array}$ \\
\hline 6/49/M & $6 \mathrm{y}, 2 \mathrm{mo}$ & $\begin{array}{l}\text { Acute type A dissection } \\
\text { Supracoronary aortic graft }\end{array}$ & $\begin{array}{l}\text { Redissection of the } \\
\text { aortic root }\end{array}$ & $\begin{array}{l}\text { Left graft occluded } \\
\text { Directly attached } \\
\text { RCA patent* }\end{array}$ & - \\
\hline $7 / 40 / \mathrm{M}$ & $4 \mathrm{y}, 4 \mathrm{mo}$ & $\begin{array}{l}\text { Progressive chronic type A } \\
\text { dissection with Marfan } \\
\text { syndrome Composite } \\
\text { aortic graft }\end{array}$ & $\begin{array}{l}\text { Periprosthetic } \\
\text { aneurysm }\end{array}$ & Both patent & $\begin{array}{l}\text { Totally thrombosed } \\
\text { periprosthetic aneurysm }\end{array}$ \\
\hline
\end{tabular}

$C T$, Computed tomography; $M$, male; $A R$, aortic regurgitation; $A V R$, aortic valve replacement; $A S$, aortic stenosis; $A V$, aortic valve; $R C A$, right coronary artery. ${ }^{*}$ Right coronary artery was directly attached to the ascending aortic homograft in this patient.

\section{CT Imaging Findings}

The CT imaging findings at the time of follow-up are listed in Table 1. A representative example of an occluded right part of the Cabrol graft is shown in Figure 1; an example of a bilaterally patent parts of the Cabrol graft is shown in Figure 2. CT showed 1 occluded (to the left main coronary artery) and 1 subtotally occluded part of the Cabrol graft (to the RCA). Six parts of the grafts to the left main coronary artery and 3 to the RCA were fully patent, similar to the 2 directly reattached RCAs. One of $7(14 \%)$ of the left and 2 of $5(40 \%)$ of the right parts of the Cabrol grafts were occluded.

\section{CFD}

Coronary flow rates. Coronary flow rates during systole and diastole for the surgical models were compared with the normal anatomy. The Valsalva graft model shows a similar overall distribution of flow through the coronary arteries as the normal anatomy, although at lesser values (Table 2). The Cabrol model gives similar flow rates for the LAD. However, lower values were found for the LCX and significantly lower flow for the RCA. Importantly, no outflow obstruction mimicking a downstream coronary stenosis was simulated in all 3 models.

Flow characteristics. The flow in the normal aortic root and Valsalva graft models are visualized using streamlines in Figure 3 for both systole and diastole. The flow at the ostium of the two geometries into the coronary arteries is remarkably smooth.

Flow into the Cabrol graft during systole shows a horizontally spiraling, corkscrew-like flow at the opening of the Cabrol graft toward the left coronary connection of the graft. Also present is a vertically spiraling flow just distal to the opening of the Cabrol graft toward the connection to the RCA (Figure 4).

A close-up view of the streamlines for the Cabrol graft connection to the native RCA shows that the flow must divert approximately $90^{\circ}$ from the inferior end of the Cabrol graft to make its way into the coronary artery.

\section{DISCUSSION}

The Cabrol procedure provides an accurate, tension-free anastomosis of the native coronary arteries to the Dacron graft that prevents formation of pseudoaneurysms at the coronary ostia. ${ }^{16}$ However, it carries the risk for various late complications such as kinking of the Cabrol graft, angulation with occlusion at the coronary artery ostia, and-most important—graft occlusion owing to thrombosis or stenosis. ${ }^{6,9,16}$ Therefore, some authors propose its use only in rare instances. ${ }^{6}$ Most of the ischemic complications related to the Cabrol procedure described in the literature occurred 

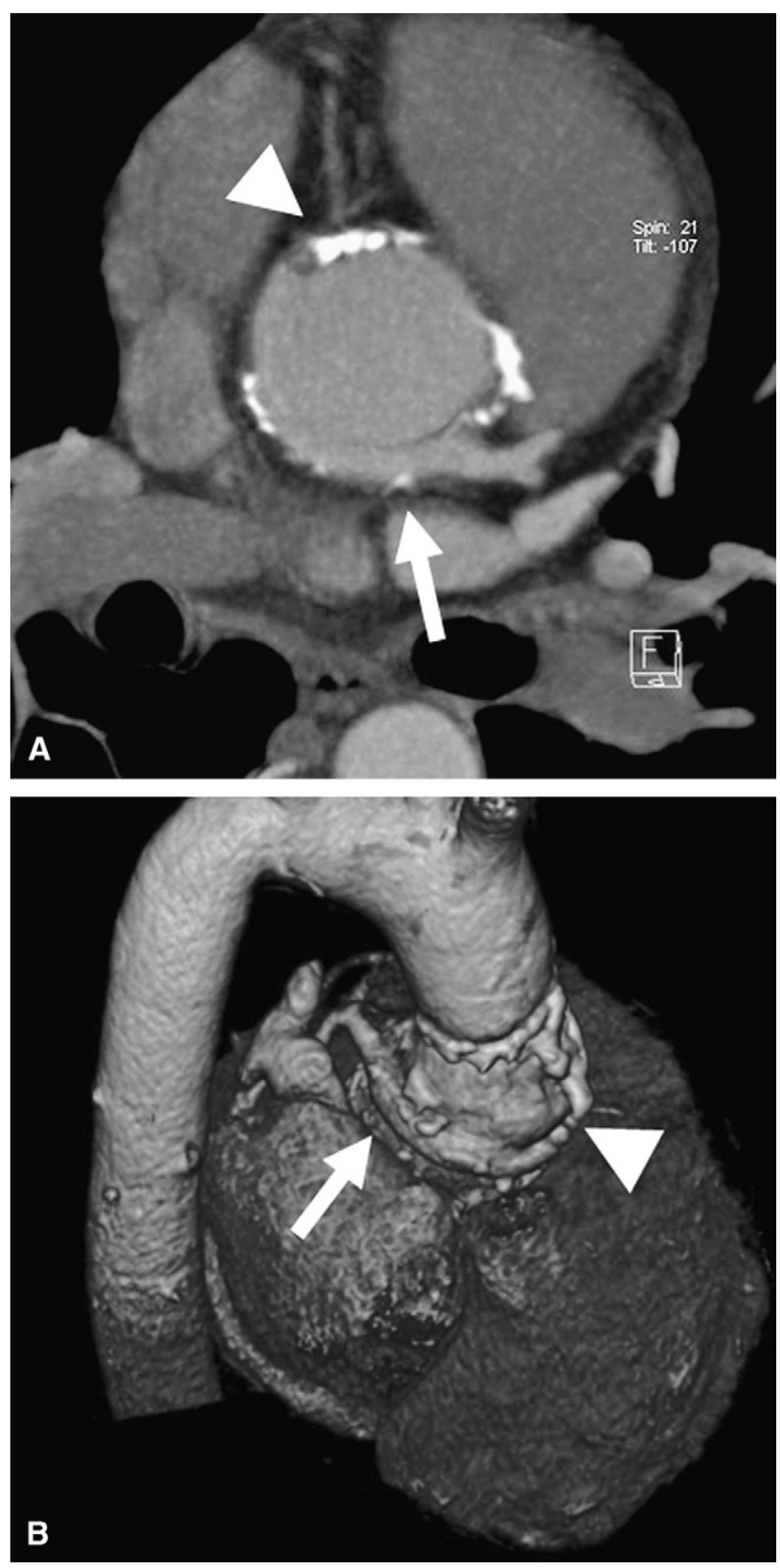

FIGURE 1. Dual-source computed tomographic angiogram in a 42-yearold man performed 7 years, 1 month after the Cabrol procedure. Transverse thin maximum-intensity projection (A) and volume-rendered images (B) demonstrate a patent Cabrol graft to the left main artery (arrows) and an occluded Cabrol graft to the right coronary artery (arrowheads).

within 5 years from the initial surgical intervention. These were due to either thrombosis or stenosis of the Cabrol graft ${ }^{6,7}$ at the anastomosis site with the native coronary arteries. Certainly, the efficacy of the Cabrol procedure is also related to technical aspects of the anastomoses. On the other hand, in our patient cohort, we found no pseudoaneurysms at the
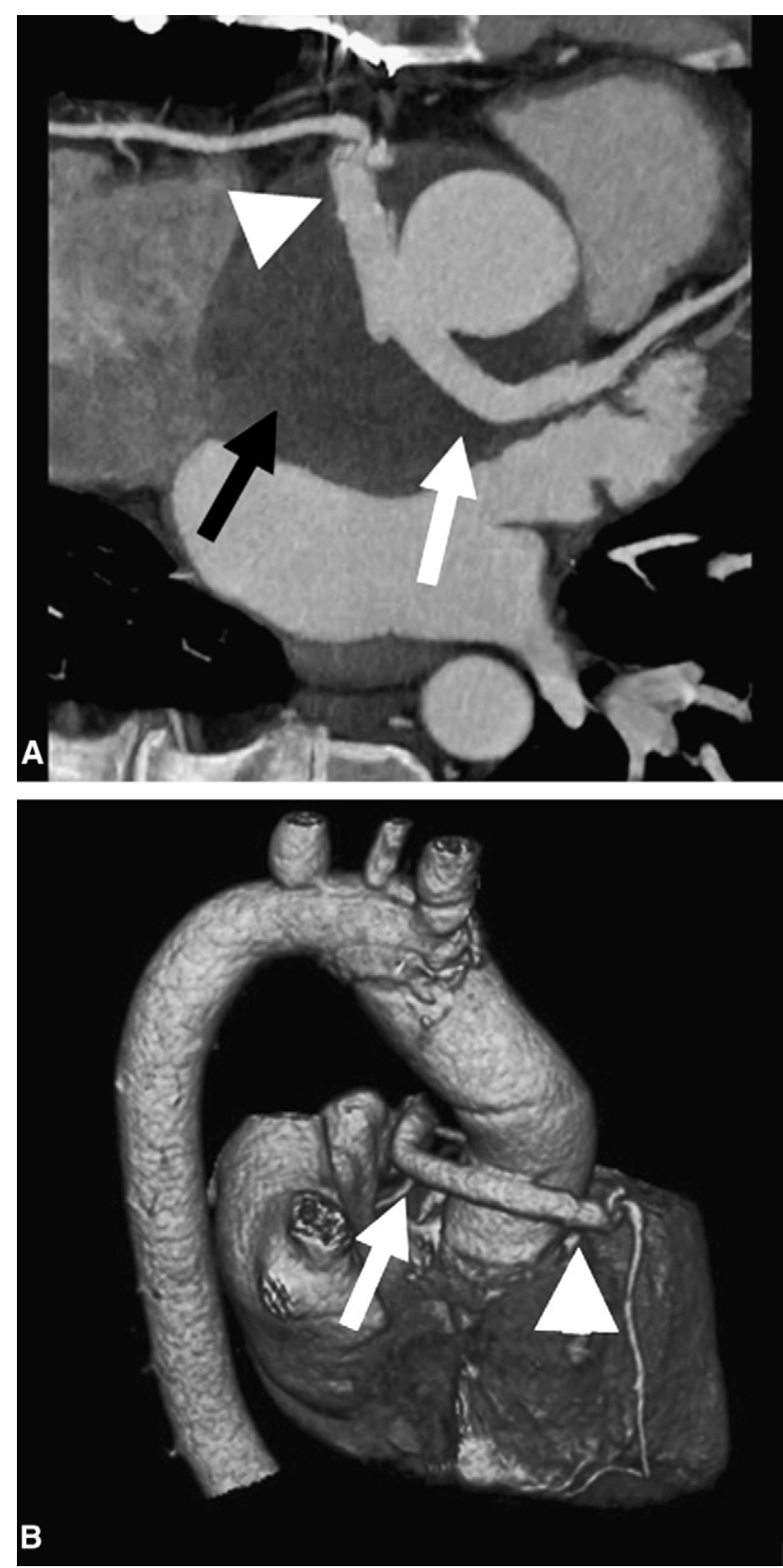

FIGURE 2. Dual-source computed tomographic angiogram in a 40-yearold man performed 4 years, 4 months after the Cabrol procedure. Transverse thin maximum-intensity projection (A) and volume-rendered images (B) demonstrate a patent Cabrol graft to the left main (white arrows) and right coronary artery (arrowheads), as well as the completely thrombosed periprosthetic aneurysm.

coronary ostia anastomoses; however, 1 of 7 of the left and 2 of 5 of the right parts of the Cabrol grafts were occluded.

Sufficient flow into the coronary arteries is important for coronary patency and overall cardiac function. The normal aortic root has evolved to provide efficient flow into the 
TABLE 2. Data for the coronary flow for each of the 3 models (ascending aorta, Valsalva graft, and Cabrol procedure) for systole and diastole

\begin{tabular}{lcccc}
\hline & \multicolumn{4}{c}{ Systolic coronary flow (mL/min) } \\
\cline { 2 - 5 } & LAD & LCX & RCA & Total \\
\hline Ascending aorta & 33 & 17 & 15 & 65 \\
Valsalva graft & 24 & 16 & 15 & 55 \\
Cabrol graft & 25 & 10 & 1 & 36
\end{tabular}

\begin{tabular}{lcccc} 
& \multicolumn{4}{c}{ Diastolic coronary flow (mL/min) } \\
\cline { 2 - 5 } & LAD & LCX & RCA & Total \\
\hline Ascending aorta & 67 & 33 & 12 & 112 \\
Valsalva graft & 58 & 32 & 8 & 98 \\
Cabrol graft & 78 & 30 & 1 & 109
\end{tabular}

\begin{tabular}{lcc} 
& \multicolumn{2}{c}{ Percentage of total coronary flow } \\
\cline { 2 - 3 } & Systolic & Diastolic \\
\hline Ascending aorta & 37 & 63 \\
Valsalva graft & 36 & 64 \\
Cabrol graft & 25 & 75
\end{tabular}

$L A D$, Left anterior descending coronary artery; $L C X$, left circumflex coronary artery; $R C A$, right coronary artery.

coronary ostium, and the results from the CFD study confirm this, while also showing that the Valsalva graft has similar flow characteristics. In both cases, the curved pouchlike structure of the native sinuses of Valsalva (normal aortic root) and the Valsalva graft, respectively, act in such a manner as to more efficiently channel flow to the cardiac tissue.

This contrasts with the Cabrol model, wherein two specific patterns of the flow are of particular interest: (1) flow into the native RCA from the Cabrol graft and (2) the spiraling flow formations in the Cabrol graft. The abrupt narrowing of the Cabrol graft part as it connects to the RCA has a considerable impact on the resulting flow into the RCA. Although the Cabrol model in this study is only a representation of a single patient having undergone a Cabrol procedure, results found in the CFD study, and in particular the low flow rates through the RCA, could partially explain the clinical findings in this (cases 1 and 5) and other studies ${ }^{17}$ showing occlusion of the right portion of Cabrol grafts.

A unique flow pattern is found in the Cabrol graft itself, especially during systole. The horizontally spiraling flow is produced by the rapid ejection of blood from the heart and past the Cabrol graft. The vertically spiraling flow on the RCA connection side of the Cabrol graft can be accounted for by an attempt of the fluid to equalize the forces (momentum) associated with the flow. These peculiar flows also likely contribute to negative outcomes of the Cabrol graft, as shown by the higher rate of RCA closure found in the clinical follow-up of our patients.

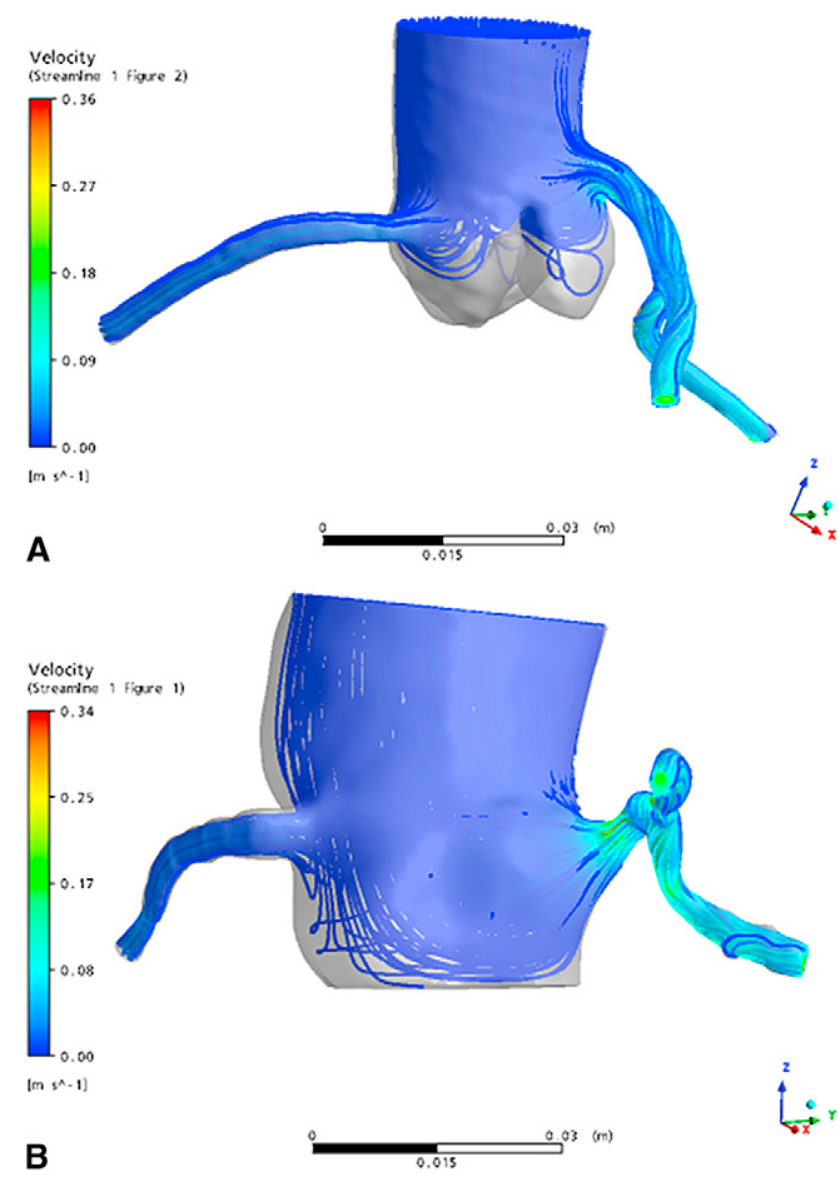

FIGURE 3. Streamlines of flow for the normal aortic root (A) and Valsalva graft (B) in diastole show similar patterns.

\section{Clinical Relevance}

Although the Cabrol procedure was widely used in the 2 decades subsequent to its development, Patel and associates ${ }^{18}$ state that "the Cabrol procedure is now forgotten by most surgeons and almost unknown by cardiologists." With the known long-term issues of the Cabrol procedure, it is of utmost importance that those who become responsible for follow-up of these patients have knowledge of the particulars of the procedure, similar to other reoperative techniques of the aortic root. ${ }^{19,20}$ There have already been several reported cases of successful follow-up treatments of Cabrol patients made with percutaneous, ${ }^{19,20}$ surgical, ${ }^{18}$ as well as combined surgical/endovascular treatments, ${ }^{21}$ and these types of interventions are likely to become more common as the patients with previous Cabrol procedures age.

Despite the limited use of the Cabrol procedure, a technique to reattach the coronary arteries during ascending aortic replacement when the button technique is not feasible is still needed. On the basis of the higher rate of occlusions of the RCA and the unique flow into the Cabrol graft, together with a patent RCA of all directly attached coronary arteries, 

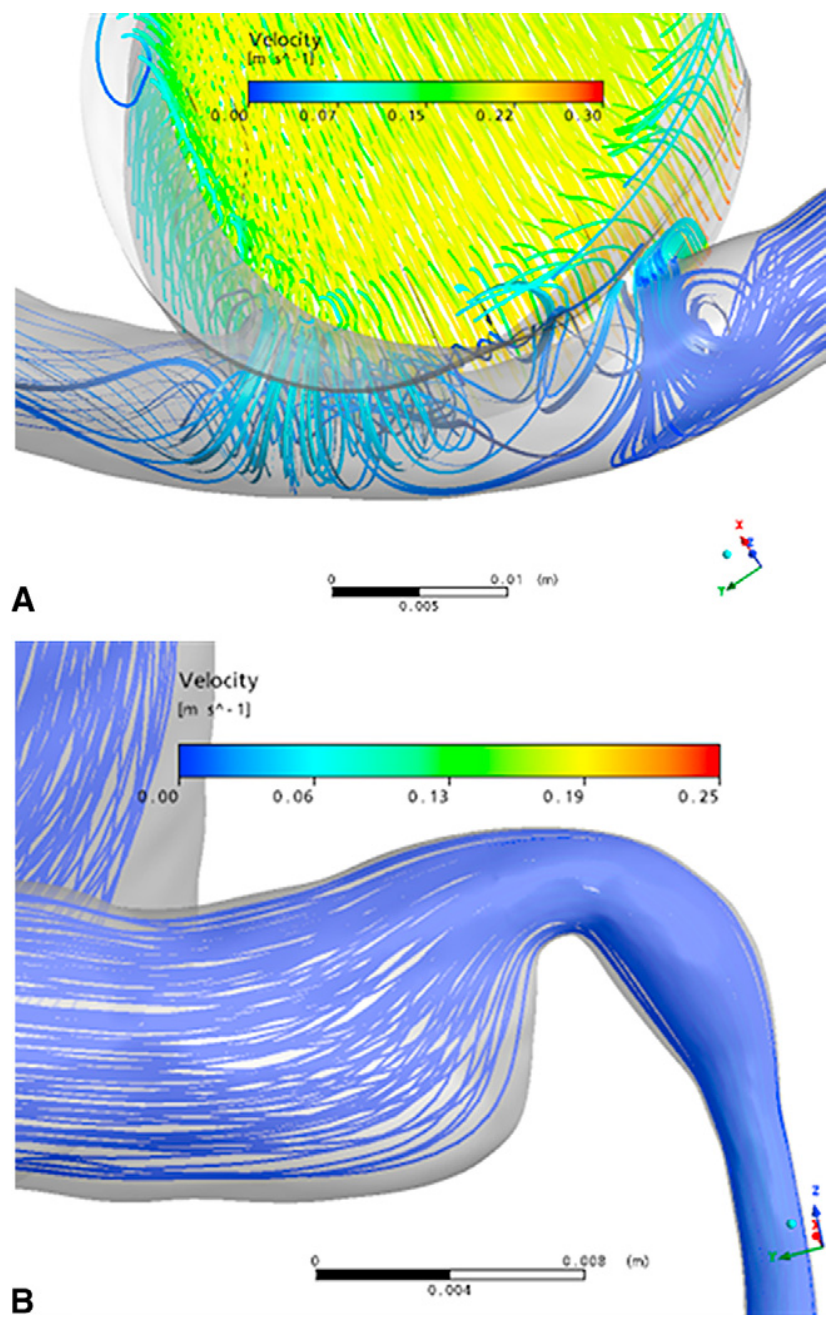

FIGURE 4. Streamlines in the Cabrol model showing spiraling flow in both the horizontal and vertical directions in the Cabrol graft (A) and flow into the right coronary artery (B).

our study suggests the use of a direct connection whenever feasible. These preliminary data warrant further investigation.

\section{Limitations}

This study is limited in the analysis of only 7 patients for long-term clinical follow-up being operated on with the Cabrol procedure. However, this procedure was rarely performed, and considering the severe morbidity and age of those patients, it is hard to obtain a larger patient cohort for follow-up. The results from the CFD study are limited in the fact that the geometry used was from a single, representative Cabrol procedure.

\section{CONCLUSIONS}

Our study provides long-term clinical and CT imaging data and demonstrates, for the first time, hemodynamic features of blood flow within the Cabrol graft. Our results from CFD analysis indicate a low and nonlaminar flow particularly into the right Cabrol graft correlating well with a higher rate of graft occlusions when compared with the left Cabrol graft side.

\section{References}

1. De Paulis R, Bassano C, Scaffa R, Nardi P, Bertoldo F, Chiariello L. Bentall procedures with a novel valved conduit incorporating "sinuses of Valsalva." Surg Technol Int. 2004;12:195-200.

2. de Paulis R, Tomai F, Bertoldo F, Ghini AS, Scaffa R, Nardi P, et al. Coronary flow characteristics after a Bentall procedure with or without sinuses of Valsalva. Eur J Cardiothorac Surg. 2004;26:66-72.

3. Gelsomino S, Frassani R, Da Col P, Morocutti G, Masullo G, Spedicato L, et al. A long-term experience with the Cabrol root replacement technique for the management of ascending aortic aneurysms and dissections. Ann Thorac Surg. 2003;75:126-31.

4. Shiono M, Hata M, Sezai A, Iida M, Negishi N, Sezai Y. Reoperation for ascending aortic aneurysm, coronary ostial aneurysm and patent Cabrol trick after Bentall operation for aortitis syndrome. Circ J. 2005;69:861-4.

5. Bachet J, Termignon JL, Goudot B, Dreyfus G, Piquois A, Brodaty D, et al. Aortic root replacement with a composite graft. Factors influencing immediate and longterm results. Eur J Cardiothorac Surg. 1996;10:207-13.

6. Cabrol C, Pavie A, Gandjbakhch I, Villemot JP, Guiraudon G, Laughlin L, et al. Complete replacement of the ascending aorta with reimplantation of the coronary arteries: new surgical approach. J Thorac Cardiovasc Surg. 1981;81:309-15.

7. Cabrol C, Pavie A, Mesnildrey P, Gandjbakhch I, Laughlin L, Bors V, et al. Longterm results with total replacement of the ascending aorta and reimplantation of the coronary arteries. J Thorac Cardiovasc Surg. 1986;91:17-25.

8. Milano AD, Pratali S, Mecozzi G, Boraschi P, Braccini G, Magagnini E, et al. Fate of coronary ostial anastomoses after the modified Bentall procedure. Ann Thorac Surg. 2003;75:1797-801; discussion 1802.

9. Westaby S, Katsumata T, Vaccari G. Aortic root replacement with coronary button re-implantation: low risk and predictable outcome. Eur J Cardiothorac Surg. 2000; 17:259-65.

10. Hilgenberg AD, Akins CW, Logan DL, Vlahakes GJ, Buckley MJ, Madsen JC, et al. Composite aortic root replacement with direct coronary artery implantation. Ann Thorac Surg. 1996;62:1090-5.

11. Alkadhi H, Scheffel H, Desbiolles L, Gaemperli O, Stolzmann P, Plass A, et al. Dual-source computed tomography coronary angiography: influence of obesity, calcium load, and heart rate on diagnostic accuracy. Eur Heart J. 2008;29:766-76.

12. Leschka S, Scheffel H, Desbiolles L, Plass A, Gaemperli O, Valenta I, et al. Image quality and reconstruction intervals of dual-source CT coronary angiography: recommendations for ECG-pulsing windowing. Invest Radiol. 2007;42:543-9.

13. Stolzmann P, Scheffel H, Schertler T, Frauenfelder T, Leschka S, Husmann L, et al. Radiation dose estimates in dual-source computed tomography coronary angiography. Eur Radiol. 2008;18:592-9.

14. Bove EL, de Leval MR, Migliavacca F, Guadagni G, Dubini G. Computationa fluid dynamics in the evaluation of hemodynamic performance of cavopulmonary connections after the Norwood procedure for hypoplastic left heart syndrome. $J$ Thorac Cardiovasc Surg. 2003;126:1040-7.

15. Boutsianis E, Dave H, Frauenfelder T, Poulikakos D, Wildermuth S, Turina M, et al. Computational simulation of intracoronary flow based on real coronary geometry. Eur J Cardiothorac Surg. 2004;26:248-56.

16. Jault F, Nataf P, Rama A, Fontanel M, Vaissier E, Pavie A, et al. Chronic disease of the ascending aorta: surgical treatment and long-term results. J Thorac Cardiovasc Surg. 1994;108:747-54.

17. Witzenbichler B, Schwimmbeck P, Schultheiss HP. Images in cardiovascular medicine. Myocardial infarction caused by occlusion of Cabrol conduit graft. Circulation. 2005;112:e79-80.

18. Patel D, Arteaga RB, Robinson VJ, Patel NA, Kapoor D. Angina, an unusual and late complication of the Cabrol procedure: a case report and review of the literature. Am J Med Sci. 2008;335:151-3. 
19. Etz CD, Plestis KA, Homann TM, Bodian CA, Di Luozzo G, Spielvogel D, et al. Reoperative aortic root and transverse arch procedures: a comparison with contemporaneous primary operations. J Thorac Cardiovasc Surg. 2008;136:860-7, e861-3.

20. Hanke T, Charitos EI, Stierle U, Robinson D, Gorski A, Sievers HH, et al. Factors associated with the development of aortic valve regurgitation over time after two different techniques of valve-sparing aortic root surgery. $J$ Thorac Cardiovasc Surg. 2009;137:314-9.

21. Gorlitzer M, Wislocki W, Meinhart J, Grabenwoger M. Treatment of chronic aortic type A dissection with a new designed hybridprosthesis. Eur J Cardiothorac Surg. 2007;31:315-7. 